\title{
PENERAPAN MODEL PEMBELAJARAN KOOPERATIF TIPE TAKE AND GIVE UNTUK MENINGKATKAN HASIL BELAJAR SISWA PADA KONSEP KLASIFIKASI MAKHLUK HIDUP DI SMP NEGERI 1 SIMPANG TIGA
}

\author{
Nurul Ulfa (1) ,Zuraida (2), Zufahmi (3) \\ 1,2,3Program Studi Pendidikan Biologi Universitas Jabal Ghafur \\ raidazuraida4@gmail.com
}

\begin{abstract}
ABSTRAK
Peneltianini berjudul "Penerapan model pembelajaran kooperatif Tipe Take and Give untuk meningkatkan hasil belajar pada konsep klasifikasi makhluk hidup di SMP Negeri 1 SimpangTiga". Pelaksanaan penelitian dilakukan di kelas VII pada semester ganjil tahun ajaran 2018/2019SMP Negeri 1 SimpangTiga. Metode penelitian menggunakan pretest-posttest control group design. Penentuan sampel dalam penelitian ini diambil dari hasil pre-test seluruh kelas VII, kemudian dipilih sebanyak dua kelas yang akan dijadikan kelas eksperimen dan kelas kontrol, yaitu kelas yang memiliki nilai rata-rata kelas yang mendekati, kemudian dipilih secara acak untuk dijadikan yang mana kelas eksperimen dan kelas kontrol. Kelas yang terpilih sebagai kelas eksperimen adalah kelas VII-A dengan jumlah siswa 28 orang, sedangkan kelas kontrol adalah kelas VII-B dengan jumlah siswa 28 orang. Pengumpulan data dengan cara dokumentasi dan tes. Teknik analisis data dengan Analisispeningkatanhasilbelajar Gain yang dinormalisasi (N-gain) dan pengujian hipotesis uji independent sample t-test ( Uji-t). Peningkatan hasil belajar menunjukkan Skor N-Gain berkategori sedang sebesar 0,68 pada kelas eksperimen dan kelas kontrol Skor N-Gain berkategori rendah dengan skor rerata 0,21. Hipotesis penelitian menggunakan uji-t diperoleh nilai $\mathrm{t}=6,90$, jadi $\mathrm{t}$ hitung $>$ ttabel yaitu 6,90 $>1,67$, dengan demikian Ha diterima dengan taraf signifikan 0,05 maka dapat disimpulkan bahwa hipotesis dapat diterima kebenarannya. Berdasarkan hasil penelitian dapat disimpulkan bahwa penerapan model pembelajaran kooperatif Tipe Take and Give dapat meningkatkan hasil belajara pada konsep klasifikasi makhluk hidup di SMP Negeri 1 Simpang Tiga.
\end{abstract}

Kata Kunci: Penrapan, kooperatif Tipe Take and Give, Klasifikasi Makhluk Hidup, Hasil Belajar siswa

\section{PENDAHULUAN}

Pendidikan memegang peranan yang sangat penting bagi kelangsungan kehidupan manusia. Berawal dari kesuksesan di bidang pendidikan suatu bangsa menjadi maju dan melalui pendidikan sumber daya manusia akan menjadi berkualitas. Menurut Munib (2009:34) pendidikan adalah usaha sadar dan sistematis, yang dilakukan oleh orangorang yang diserahi tanggung jawab untuk mempengaruhi peserta didik agar mempunyai sifat dan tabiat sesuai dengan cita-cita pendidikan. Proses interaksi belajar mengajar adalah inti dari kegiatan pendidikan, proses belajar mengajar sebaiknya selalu mengikut sertakan peserta didik secara aktif guna mengembangkan kemampuan mengamati, merencanakan, meneliti, dan menemukan hasil sehingga guru mengetahui kesulitan yang dialami oleh peserta didik dan selanjutnya mencari solusi yang tepat.

Berdasarkan hasil observasi yang dilakukan oleh peneliti disemua kelas VII SMP Negeri 1 Simpang Tiga dalam pembelajaran IPA di peroleh gambaran bahwa guru masih mendominasi menggunakan metode pembelajaran yang konvesional. Guru tersebut sering sekali menggunakan metode ceramah dan tanya jawab dalam menyampaikan materi, 
kemudian peserta didik mencatat uraian materi tersebut ke dalam buku catatan. Hal ini mengakibatkan siswa merasa kurang tertarik dengan materi pelajaran yang disajikan oleh guru. Peserta didik yang bersifat pasif menyebabkan kejenuhan dalam proses pembelajaran dan tidak adanya interaksi antar peserta didik dengan guru.

Tujuan pembelajaran IPA pada materi klasifikasi makhluk hidup adalah peserta didik dapat mengklasifikasikan makhluk hidup dan benda tak hidup berdasarkan karakterisrik yang diamati, kemudian peserta didik dapat menerapkan materi yang didapatkan dalam kehidupannya. Agar tujuan tercapai dengan baik, pembelajaran IPA tidak hanya menekankan pada penyampaian meteri, dan peserta didik hanya meneriman materi yang disampaikan tanpa ada keterlibatan peserta didik untuk berfikir luas. Pembelajaran IPA seperti ini mengakibatkan hasil belajar peserta didik menurun.

Model berperan sebagai rambu-rambu atau bagaimana memproses pembelajaran sehingga dapat berjalan dengan baik dan sistematis. Upaya untuk mengatasi permasalah yang dihadapi yaitu menurunnya hasil belajar siswa. Model pembelajaran kooperatif tipe take and give dapat dijadikan salah satu alternatif dalam meningkatkan hasil belajar siswa. Model pembelajaran kooperatif tipe take and give (memberi dan menerima) merupakan model pembelajarn yang memiliki langkahlangkah, yang menuntut siswa mampu memahami materi pelajaran yang diberikan guru dan teman sebayanya. Media yang digunakan dalam model kooperati tipe take and give adalah kertas yang berbentuk seperti kartu yang ukurannya sudah di tentukan.

Model pembelajaran kooperati tipe take and give merupakan salah satu model yang dapat digunakan guru dalam mencapai tujuan pembelajaran. Pembelajaran IPA dengan model pembelajaran kooperatif tipe take and give melatih peserta didik bersosialisasi sesama teman, dengan cara peserta didik menyampaikan materi yang diberikan guru dan menyampaikan materi kepada sesama teman, dan semakin banyak materi yang disampaikan maka peserta didik semakin memahami materi dan peserta didik dapat mengembangkan pengetahuannya yang pada akhirnya mempengaruhi hasil belajar peserta didik.

Pembelajaran IPA dengan menggunakan model pembelajaran take and give, aktivitas belajar lebih banyak berpusat pada peserta didik. Pembelajaran ini guru hanya bertindak sebagai penyampaian informasi, fisilitator dan pembimbing. Suasana pembelajaran yang dibentuk untuk saling bersaing untuk menyampaikan materi kepada teman sebayanya yang membuat peserta didik termotivasi untuk belajar menyampaikan sesuatu yang baik dan benar, dengan memberikan pembelajaran yang aktif seperti kooperatif tipe take and give ini pada peserta didik dapat membantu ingatan (memori) mereka, sehingga mereka dapat dihantarkan kepada tujuan pembelajaran dengan sukses.

Berdasarkan reverensi yang relevan, Udayati (2017) menyatakan bahwa penerapan model pembelajaran Take And Give dapat meningkatkan hasil belajar IPA siswa kelas IVA.Adiani(2016) menyatakan bahwa penerapan model pembelajaran Take And Give dapat meningkatkan hasil belajar IPA siswa kelas IV SD Negeri 1 Penglatan. Septiana(2017) menyatakan bahwa pengaruh penggunaan model kooperatif Tipe Take And Give terhadap hasil belajar IPS terpadu siswa kelas VIII semester genap SMP Muhamadiyah 1 Merto.

Berdasarkan permasalahan tersebut maka peneliti ingin melakukan penelitian dengan judul penerapan model pembelajaran kooperatif tipe take and give dalam peningkatkan hasil belajar siswa pada konsep klasifikasi makhluak hidup di SMP Negeri 1 Simpang Tiga.Berdasarkan uraian latar belakang di atas, masalah dalam penelitian ini adalah "Apakah Penerapan model pembelajaran kooperatif tipe take and give untuk meningkatkan hasil belajar siswa pada konsep klasifikasi makhluk 
hidup di SMP Negeri 1 Simpang Tiga?'Penelitian ini bertujuan untuk mengetahui penerapan model pembelajaran kooperatif tipe take and give dalam peningkatan hasil belajar siswa pada konsep klasifikasi makhluk hidup di SMP Negeri 1Simpang Tiga. Berdasarkan rumusan masalah dan tujuan penelitian yang telah diuraikan di atas, maka hipotesis penelitian ini adalah penerapan model pembelajaran kooperatif tipe take and give pada konsep klasifikasi makhluk hidup dapat meningkatkan hasil belajar siswa di SMP Negeri 1 Simpang Tiga.

\section{METODE PENELITIAN \\ Jenis dan pendekatan penelitian}

Penelitian ini merupakan jenis penelitian kuantitatif, penelitian kuantitatif digunakan untuk mendeskripsikan sejauh mana peningkatan respon dan hasil belajar siswa dalam pembelajaran pada konsep klasifikasi makhluk hidup. Menurut Margono (2003:105):Pengertian Kuantitatif adalah suatu proses menemukan pengetahuan yang menggunakan data berupa angka sebagai alat menemukan keterangan mengenai apa yang diketahui, dan penelitian kuantitatif ini bertumpu sangat kuat pada pengumpulan data berupa angka hasil pengukuran, karena itu data yang terkumpul harus diolah secara statistik agar dapat di tafsir dengan baik.

Pendekatan kuantitatif menggunakan tes tulis sebagai intrumen penelitian, tes dibuat dalam bentuk pilihan ganda yang bersumber pada tujuan pembelajaran, khususnya pada materi klasifikasi makhluk hidup. Perangkat tes yang disusun tersebut kemudian diberikan kepada siswa yang menjadi subjek penelitian.

Metode penelitian menggunakan metode eksperimen, metode eksperimen adalah suatu penelitian ilmiah dimana peneliti memanipulasi dan mengontrol satu atau lebih variabel bebas dan melakukan pengamatan terhadap variabel-variabel terikat untuk menemukan variasi yang muncul bersamaan dengan manipulasi terhadap variabel bebas tersebut. Lebih lanjut dijelaskan, variabel yang dimanipulasi disebut variabel bebas dan variabel yang akan dilihat pengaruhnya disebut variabel terikat (Kerlinger 2006: 315)

Metode penelitian eksperimen memiliki bermacam-macam jenis desain. Metode eksperimen dalam penelitian ini menggunakan jenis desain penelitian dengan metode pretest-posttest control group design. Dalam desain ini, Sugiyono menyatakan "bahwa terdapat dua kelompok yang dipilih secara random, yang sebelumnya diberi pretest untuk mengetahui keadaan awal antara kelompok eksperimen dan kelompok kontrol" (Sugiyono, 2012:112). Selanjutnya setelah diketahui hasil dari pretest dua kelompok tersebut, maka pada kelas eksperimen diberikan perlakuan $(\sqrt{ })$, sedangkan pada kelas kontrol tidak diberikan perlakuan (X).

Control group design seperti pada Tabel 3.1 .

Table 3.1 Desain Penelitian

\begin{tabular}{|c|c|c|c|}
\hline Subjek & Pretest & Perlakuan & Postest \\
\hline $\begin{array}{c}\text { Kelas } \\
\text { eksperimen }\end{array}$ & $\mathrm{O}_{1}$ & $\sqrt{ }$ & $\mathrm{O}_{2}$ \\
\hline Kelas control & $\mathrm{O}_{2}$ & $\mathrm{X}$ & $\mathrm{O}_{2}$ \\
\hline
\end{tabular}

Keterangan: $(\sqrt{ })$ : perlakuan kelas

eksperimen

$\mathrm{X}$ : perlakuan kelas kontrol

$\mathrm{O} 1$ :pretest

$\mathrm{O} 2$ : post test

\section{TempatdanWaktu}

Penelitian dilaksanakan di kelas VII SMP Negeri 1 SimpangTiga pada semester ganjil tahun ajaran 2018/2019.

\section{Populasi dan Sampel \\ Populasi}

Pada penelitian ini yang menjadi populasi adalah seluruh siswa Kelas VII SMP Negeri 1 Simpang Tiga. Tahun Ajaran 2018/2019, yang terdiri dari 7 kelas dengan jumlah siswa 206 orang. 


\section{Sampel}

Penentuan sampel dalam penelitian ini diambil dari hasil pre-test seluruh kelas VII, kemudian dipilih sebanyak dua kelas yang akan dijadikan kelas eksperimen dan kelas kontrol, yaitu kelas yang memiliki nilai ratarata kelas yang mendekati, kemudian dipilih secara acak untuk dijadikan yang mana kelas eksperimen dan kelas kontrol. Kelas yang terpilih sebagai kelas eksperimen adalah kelas VII-A dengan jumlah siswa 28 orang, sedangkan kelas kontrol adalah kelas VII-B dengan jumlah siswa 28 orang. Setelah menentukan kelas eksperimen dan kontrol, maka dilakukan proses pembelajaran dengan model Take and Give untuk kelas eksperimen dan metode ceramah dan diskusi untuk kelas kontrol.

\section{ProsedurPenelitian}

Pelaksanaan penelitian diperlukan adanya data dan informasi untuk pembuatan laporan yang dilakukan secara bertahap, dimulai dengan melakukan identifikasi kompetensi inti dan kopetensi dasar, perumusan indikator, memilih model pembelajaran, penyusunan perangkat, revisi, menerapkan model pembelajaran, analisis hasil penerapan model pembelajaran, laporan. Untuk lebih jelasnya dapat dilihat gambar 3.2 seperti berikut.

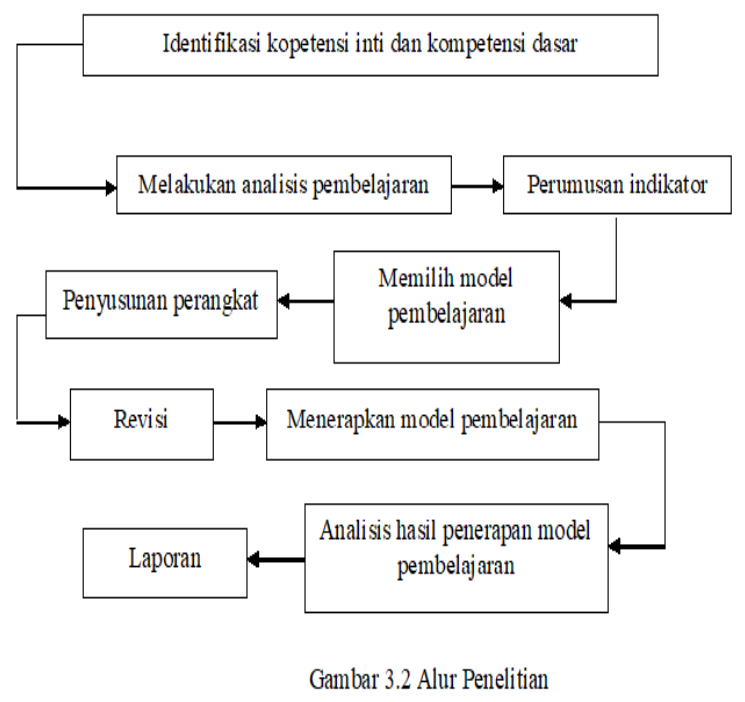

\section{Teknik pengumpulan data}

Adapun teknik pengumpulan data dalampenelitian dengan dokumentasi dan tes.

\section{Teknik Analisis Data}

\section{Analisispeningkatanhasilbelajar}

Gain yang dinormalisasi (N-gain) dapatdihitungdenganpersamaan: (Hake, 1999)

$$
\begin{aligned}
& N-\text { Gain } \\
& =\frac{(\text { S Posttes }-S \text { Pretes })}{(\text { S Maksimum }-S \text { Pretes })}
\end{aligned}
$$

Data dari hasil perhitungan $\mathrm{N}$-gain tersebut kemudian dikonversi dengan kriteria sebagai berikut:

Tabel 3.4.Kriteria normalized gain

\begin{tabular}{|l|c|}
\hline \multicolumn{1}{|c|}{ Skor N-Gain } & Kriteria \\
\hline $0.70<N$-Gain & Tinggi \\
\hline $0.30 \leq N$-Gain $\leq 0.70$ & Rendah \\
\hline$N$-Gain $<0.30$ & Sedang \\
\hline
\end{tabular}

(Diadaptasi dari Hake, 1999 dalam Zuraida, 2019)

\section{Analisis perbedaan hasil belajar}

rumus uji independent sample t-test ( Uji-t) :

$$
t=\frac{\overline{\mathrm{x}}_{1}-\overline{\mathrm{x}}_{2}}{\mathrm{~s} \sqrt{\frac{1}{\mathrm{n}_{1}}+\frac{1}{\mathrm{n}_{2}}}}
$$

Keterangan:

$\mathrm{t}=$ harga $\mathrm{t}$ yang dihitung

$\overline{\mathbf{x}}_{1}=$ rata-rata nilai tes dari kelompok

$$
\text { eksperimen }
$$

$\overline{\mathbf{x}}_{2}=$ rata-rata nilai tes dari kelompok kontrol

$\mathrm{n}_{1}=$ jumlah siswa kelompok eksperimen

$\mathrm{n}_{2}=$ jumlah siswa kelompok kontrol (Sudjana, 2005:91)

\section{HASIL DAN PEMBAHASAN}

Berdasarkan hasil penelitian yang telah dilakukan penulis pada kelas kontrol sebelum dilakukan proses pembelajaran nilai rata-rata pre-tes 1,65 dan setelah dilakukan pembelajaran dengan model konvesional nilai rata-rata post-tes siswa sebesar 2,18. Pada kelas eksperimen 
sebelum dilakukan proses pembelajaran nilai rata-rata siswa sebesar 1,55 dan setelah dilakukan pembelajaran dengan model pembelajaran kooperatif tipe take and give nilai rata-rata post-tes sebesar 3,20.Artinya terdapat peningkatan hasil belajar siswa secara signifikan pada kelas eksperimen dengan menggunakan model pembelajaran kooperatif tipe take and give dibandingkan dengan kelas kontrol yang menggunakan metode konvensional pada konsep klasifikasi makhluk hidup di SMP Negeri 1 Simpang Tiga. Dengan nilai rata-rata sebesar 3,20 untuk kelas eksperimen dan 1,55 untuk kelas kontrol. Hasil analisis statistik dengan menggunakan uji-t diperoleh nilai $t_{\text {hitung }}>t_{\text {tabel }}$ pada taraf signifikan $\alpha 0,05$ yaitu $6,90>1,67$, sehingga dari kriteria pengujiannya $\mathrm{Ha}$ diterima, artinya penerapan model pembelajaran kooperatif tipe take and give dapat menungkatkan hasil belajar siswa pada konsep klasifikasi makhluk hidup di SMP Negeri 1 Simpang Tiga. Model pembelajaran kooperati tipe take and give memberikan kesempatan kepada siswa untuk lebih aktif selama kegiatan pembelajaran berlangsung. Komponen penting dalam model pembelajaran kooperatif tipe take and give adalah penguasaan materi melalui kartu, keterampilan bekerja dalam kelompok dan bertukar informasi, serta evaluasi yang bertujuan untuk mengetahui pemahaman atau penguasaan siswa terhadap materi yang diberikan di dalam kartu dan kartu pasangannya.Take and give mempunyai arti menerima dan memberi, maksud take and give dalam model pembelajaran ini adalah siswa saling menerima dan memberi pelajaran pada siswa yang lainnya berdasarkan pembagian tugas yang jelas. Siswa mengajar teman sebaya dengan pembagian seperti ini dapat memberikan kesempatan kepada siswa untuk mempelajari sesuatu saat menjadi narasumber bagi siswa yang lain.Berdasarkan reverensi yang relevan, Udayati (2017) menyatakan bahwa penerapan model pembelajaran Take And
Give dapat meningkatkan hasil belajar IPA siswa kelas IVA.Adiani(2016) menyatakan bahwa penerapan model pembelajaran Take And Give dapat meningkatkan hasil belajar IPA siswa kelas IV SD Negeri 1 Penglatan. Septiana(2017) menyatakan bahwa pengaruh penggunaan model kooperatif Tipe Take And Give terhadap hasil belajar IPS terpadu siswa kelas VIII semester genap SMP Muhamadiyah 1 Merto. Berdasarkan pembahasan diatas, secara umum dapat disimpulkan bahwa penerapan model pembelajaran kooperatif tipe Take and Give pada konsep klasifikasi makhluk hidup dapat meningkatkan hasil belajar siswa di SMP Negeri 1 Simpang Tiga.

\section{SIMPULAN DAN SARAN Simpulan}

Berdasarkan hasil penelitian yang telah di bahas pada bab sebelumnya, peneliti dapat menyimpulkan bahwa:

1. Berdasarkan hasil penelitian dengan menggunakan uji- $\mathrm{t}$ diperoleh nilai $\mathrm{t}=$ 6,90 , jadi $t_{\text {hitung }}>t_{\text {tabel }}$ yaitu $6,90>1,67$, dengan demikian Ha diterima dengan taraf signifikan $\alpha 0,05$ maka dapat disimpulkan bahwa hipotesis berbunyi "Penerapan model pembelajaran kooperatif tipe Take and Give pada konsep klasifikasi makhluh hidup dapat meningkatkan hasil belajar di SMP Negeri 1 Simpang Tiga" dapat diterima kebenarannya.

2. Penerapan model kooperatif tipe Take and Give dapat meningkatkan hasil belajar siswa pada konsep klasifikasi makhluk hidup dibandingkan dengan penerapan model konvensional pada siswa di SMP Negeri 1 Simpang Tiga.

\section{Saran}

1. Dengan adanya suatu model pembelajaran kooperatif tipe Take and Give yang diterapkan oleh guru di dalam pembelajaran diharapkan dapat meningkatkan dan membangkitkan minat serta keaktifan belajar siswa terhadap mata pelajaran biologi 
sehingga dapat meningkatkan hasil belajar.

2. Karena pembelajaran dengan menggunakan model pembelajaran kooperatif tipe Take and Give memerlukan waktu yang lebih banyak, maka dalam pelaksanaannya guru diharapkan dapat mengefektifkan waktu dengan sebaik-baiknya.

3. Bagi peneliti selanjutnya peneliti dapat melakukan penelitian dengan menerapkan model pembelajaran kooperatif tipe Take and Give pada pembelajaran biologi dengan materi yang berbeda atau pada mata pelajaran yang lain.

\section{DAFTAR PUSTAKA}

Adiani, N.P.W., Ni Ketut Suarni., dan Putu Nanci Riastini. 2016. Penerapan Metode Take And Give Untuk Meningkatkan Hasil Belajar Ipa Siswa Kelas Iv Sd Negeri 1 Penglatan. e-Journal PGSD. 06:110

Anjani, D., Imam Suyanto., dan Suripto. 2015/2016. Penerapan Model Take And Give Dengan Media Grafis Dalam Peningkatan Pembelajaran Ips Tentang Persiapan Kemerdekaan Indonesia Pada Siswa Kelas V Sdn 1 Tambakagung. Kalam Cendekia. 04:481 - 487

Asniwati., dan Muhammad Syarif Faisal. 2013. Meningkatkan Hasil Belajar PKN Materi Sistem Pemerintah Pusat Melalui Kombinasi Model Group Investigasion dan Take And Give Pada Siswa Kelas IV SDN Beragas 1 Barito Kuala. Jurnal Paradigma. 08:157-170

Aqib., dan Zainal. 2013. Model-model, Media, dan Strategi Pembelajaran Kontekstual (Inovatif). Bandung : Yrama Widya.
Campbell, N. A., Reece, J.B.,\& Mitchell. L. G. 2010. Biologi Jilid 3 Edisi kedelapan. Jakarta: Erlangga.

Hamdani. 2011. Strategi Belajar Mengajar. Bandung: Pustaka Setia.

Hartami,P., Ramli Abdullah., dan Yeni Safitri. 2014. Penerapan Model Pembelajaran Kooperatif Tipe Take and Give Pada Materi Minyak Bumi Di Kelas X Man Sabang. Jurnal Lantanida. 02:171184

Huda, Miftahul. 2013. Model-Model Pengajaran dan Pembelajaran. Yogyakarta: Pustaka Pelajar.

Huda, Miftahul. 2014. Model-Model Pengajaran dan Pembelajaran: Isu-isu Metodis Paradikmatis. Yogyakarta: Pustaka Pelajar.

Ikawati, H.D. 2016. Pengaruh Model Pembelajaran Take And Give Dalam Meningkatkan Hasil Belajar Siswa. Jurnal Penelitian Dan Pengembangan Pendidikan. 03:5459

Indrakusuma., dan Amir Daien. 1993. Evaluasi Pendidikan. Malang: UIN-Malang Pers.

Isjoni. 2013. Pembelajaran Kooperatif. Yogyakarta: Pustaka Pelajar.

Munib., dan Achmad. 2009. Pengantar Ilmu Pendidikan. Semarang: UPT UNNES Press.

Riani,N., Eko Supraptono., dan Muljadi. 2016. Penerapan Model Pembelajaran Take And Give Dalam Materi Ajar Media Komunikasi Data Jaringan. Jurnal Praktik Penelitian Tindakan. 06:815 
Riduwan. 2013. Skala pengukuran variabelvariabel penelitian. Bandung: Alfabeta.

Romlah,S., dan Nuri Wahidatun Salihah. 2016. Penerapan Model Take and Give Untuk Meningkatkan Pemahaman pada Materi Asmaul Husna Kelas II di MI Darul Ulum Tambak Rejo. Jurnal Penelitian. 07:247-260

Rusman. 2012. Model-Model Pembelajaran. Depok: PT Rajagrafindo Persada

Sardiman. 2011. Interaksi \& Motivasi Belajar Mengajar. Jakarta: PT Raja Gavindo Persada.

Septiana,A., dan Ningrum. 2017. Pengaruh Penggunaan Model Cooperatif Learning Tipe Take And Give Terhadap Hasil Belajar IPS Terpadu Siswa Kelas VIII Semester Genap SMP Muhamadiyah 1 Merto. Jurnal Pendidikan. 05:76-83

Sri Yuliastini, N.L.G., Dewa Kade Tastra., dan Why Romi Sudhita. 2015. Pengaruh Model Take and Give Berbantuan Multimedia Interaktif Terhadap Hasil Belajar IPS. Jurnal Teknologi Pendidikan. 03
Subandi. 2010. Mikrobiologi. Bandung: PT Remaja Rosdakarya

Sudjana. 2005. Metode Statistika Edisi ke-6. Bandung: Tarsito

Suprijono,A. 2012. Cooperative Learning Teori dan Aplikasi PAIKEM. Yogyakarta: Pustaka Pelajar

Susanto,R., Rochima,E., Surtiretna,N., Kamil,I., dan Purwanto. 2007. EnsiklopediaBiologi. Bandung: PT Kiblat Buku Utama

Suyatno. 2009. Menjelajah Pembelajaran Inovatif. Sidoarjo Masmedia Busana Pustaka

Udayanti, S., dan Nanci Riastini. 2017. Penerapan Metode Take And Give Untuk Meningkatkan Hasil Belajar Ipa Siswa Kelas Iva. Jurnal Ilmiah Sekolah Dasar. 01: 51-58

Zuraida. 2019. Pengembangan Perangkat Pembelajaran IPA Model Learning Cycle 5E Untuk Melatihkan Kemampuan Berpikir Kreatif Siswa SMP Negeri 2 Kembang Tanjong. Jurnal Sains Riset. ISSN: 2088-0952 